Research Article

\title{
Chemical and Structural Changes of Ozonated Empty Fruit Bunch (EFB) in a Ribbon-Mixer Reactor
}

\author{
Nurul Suhada Abdur Rasid1,2, Amnani Shamjuddin1, Nor Aishah Saidina Amin",*) \\ ${ }^{1}$ Chemical Reaction Engineering Group (CREG), School of Chemical and Energy Engineering, \\ Faculty of Engineering, Universiti Teknologi Malaysia, 81310 UTM Johor Bahru, Johor, Malaysia. \\ ${ }^{2}$ Faculty of Chemical Engineering, Universiti Teknologi MARA, Johor Branch, Pasir Gudang Campus, \\ Jalan Purnama, Bandar Seri Alam, 81750 Masai, Johor, Malaysia.
}

Received: $2^{\text {nd }}$ March 2021; Revised: 21st April 2021; Accepted: 23rd Apr 2021

Available online: 25th April 2021; Published regularly: June 2021

\begin{abstract}
Agricultural wastes especially empty fruit bunch (EFB) are abundantly available to be utilized as a feedstock for biochemical synthesis or biofuel production. The components of the waste include lignin, hemicellulose and cellulose. Cellulose, the polymer of glucose, is the active component for producing bio-based chemicals. However, it is difficult to isolate cellulose since lignin, the most outer layer in the waste is recalcitrant. Therefore, the agricultural wastes need to be pre-treated prior to downstream processing. The aim of this study was to investigate the effect of ozone pretreatment on lignin degradation and total reducing sugar (TRS) yield. EFB was pre-treated using ozone gas in a ribbon-mixer reactor. The chemical and structural changes of ozonated EFB were analysed. The highest delignification obtained were $95.7 \mathrm{wt} . \%$ and TRS yield was enhanced to $84.9 \%$ at a moisture content of 40 wt.\% with $60 \mathrm{~g} / \mathrm{m}^{3}$ ozone concentration within one hour of reaction time. Both NMR and FTIR spectra conferred major peaks inferring higher lignin degradation could be achieved using ozonolysis.
\end{abstract}

Copyright (C) 2021 by Authors, Published by BCREC Group. This is an open access article under the CC BY-SA License (https://creativecommons.org/licenses/by-sa/4.0).

Keywords: Ozone; Oil Palm Biomass; Pre-treatment; Delignification; Empty Fruit Bunch

How to Cite: N.S. Ab Rasid, A. Shamjuddin, N.A.S. Amin (2021). Chemical and Structural Changes of Ozonated Empty Fruit Bunch (EFB) in a Ribbon-Mixer Reactor. Bulletin of Chemical Reaction Engineering \& Catalysis, 16(2), 383-395 (doi:10.9767/bcrec.16.2.10506.383-395)

Permalink/DOI: https://doi.org/10.9767/bcrec.16.2.10506.383-395

\section{Introduction}

Biomass is one of the renewable energies that has huge potential to be utilize as natural source of fuel and energy. It is widely available, sustainable, and also cheap. Around five million tons of biomass comprises of organic materials from grasses, trees, flowers and agricultural wastes, such as: residues from sawmills, corncob, sugarcane bagasse, oil palm waste, wheat straw, and rapeseed oil pressing, were produced

\footnotetext{
* Corresponding Author.

Email: noraishah@cheme.utm.my (N.A.S. Amin);

Tel: +6075535579; Fax: +6075588166
}

annually [1]. It consists of high molecular weight compounds, such as: lignin, cellulose, hemicellulose, and other nutrients, such as: lipids, phenolic compounds, pectin, and proteins. These natural compounds have a huge potential to be utilized for various industries including food and beverages, coatings, paints, cosmetic and pharmaceutical.

Besides, lignocellulosic biomass has huge potential to be utilized as raw material for secondgeneration biofuels, such as: methane [2], biodiesel [3], biohydrogen [4], and bioethanol, thus creating sustainable biomass supply chains by adopting "waste-to-wealth". Unfortunately, the 
utilization of biomass for bio-chemical and biofuel production has not been well-established yet.

In Malaysia, about 420 oil palm mills process fresh fruit bunches (FFB) to produce crude palm oil, and almost $70 \%$ of FFB are turned into wastes in the form of empty fruit bunch (EFB), fibers and shells, as well as liquid effluent [5]. These by-products can be converted to higher value-added products or energy to generate additional profit for the palm oil industry [6]. Among the wastes, the EFB is underutilized and some of it is currently used either as mulching material or sometimes fed into the boiler as a low energy-efficiency combustion fuel [7]. Currently, most EFB is left to decompose near the mill due to its high moisture content. This could cause detrimental effect to the environment.

One of the main constraints to utilize EFB for industrial application is the needs for pretreatment steps to break down the recalcitrant structure of lignocellulose into its fibrous components of holocellulose and lignin. It is due to low efficiency of enzymatic hydrolysis of polysaccharide which can be influenced by several factors including particle size, lignin content and cellulose degree of polymerization [8]. Among these factors, lignin content has the most significant impact on biomass degradability since the lignin removal promotes binding of enzymes and increases the total reducing sugar yield [9], hence the best pretreatment should maximize lignin removal.

Various pre-treatment methods have been developed, including biological, chemical and physical methods, as well as combinations of these methods, with the goal to find the most suitable and efficient pre-treatment steps to degrade biomass. Among those pretreatments, ozonolysis is one of the most promising pretreatment methods since it can effectively delignify biomass (up to $85 \%$ ) with minimal impact on cellulose. The ozone acts as a strong oxidative agent that attacks the electron rich lignin component of the biomass and exposed the fibrous components of hemicellulose and cellulose. Many types of agroindustry waste such as cereal straw [10], wood pulp and wood chips [11], cotton stalk [12], grass [13], among others, have been investigated for their behaviors and characteristics using ozone pretreatment and showed promising results.

There are many research findings reporting on the effectiveness of ozonated biomass in enhancing product efficiency and yield. The ozonated samples have been studied for biofuel production via fermentation process for bioeth- anol production [14,15], biohydrogen production [16], and anaerobic digestion process for methane production [17]. In addition, the ozonated biomass has also been studied in the waste water treatment plant [18]. Therefore, the ozone pretreatment is a suitable candidate to be used as pretreatment method of biomass for industrial applications.

The effectiveness of ozonolysis pretreatment depends on the reactor design, which affects ozone consumption, sugar release, and reaction kinetics by the contact between ozone with substrate. In the previous study on ozonolysis of wheat straw using fixed bed reactor [19], 50\% delignification was achieved at operating parameter of $40 \%(\mathrm{w} / \mathrm{w})$ moisture for $2 \mathrm{~h}$ reaction time. The reaction consumed $100 \%$ ozone in the first $60 \mathrm{~min}$ and gradually decreased once breakthrough time was attained. Previous studies by Vidal and Molinier [19] concluded that the stirred semi batch reactor provided higher ozone concentration compared to the fixed bed reactor, while Cesaro and Belgiorno [20] investigated the ozonolysis of municipal solid waste using Drechsel trap reactor and bubble column reactor. The bubble column reactor was more effective as higher amount of ozone reacted with the substrate while Drechsel trap obtained poor ozone contact with substrate and yielded high residual ozone [21]. Hence, in this study, the ribbon-mixer reactor was designed and used to improve the ozone distribution to enhance ozone contact with the substrate in order to favor the oxidation reaction.

In this work, lignin degradation and total reducing sugar of untreated sample (raw) and ozone treated EFB (OTE) were studied using the novel ribbon-mixer reactor. The major components were analyzed using NMR, FTIR, SEM-EDX to monitor the impact of ozone oxidation on samples. The insights of lignin modification through ozone pre-treatment could provide useful information for the development of ozonolysis pre-treatment process and its product characteristics.

\section{Materials and Methods}

\subsection{Materials}

The EFB sample was collected at palm oil mill located at Penggeli, Kulai, Johor, Malaysia in shredded form. The particle size of EFB was reduced to $0.3 \mathrm{~mm}$ and $0.5 \mathrm{~mm}$. The $\mathrm{EFB}$ was then dried in the oven at $105{ }^{\circ} \mathrm{C}$ for $24 \mathrm{~h}$ to eliminate excess moisture and stored in sealed container to prevent microorganism growth and further characterization. 
All chemicals used in the experiments were of analytical reagent grade. Sulphuric acid $\left(\mathrm{H}_{2} \mathrm{SO}_{4}, 95-98 \%\right.$, Qrec, NZ), sodium carbonate $\left(\mathrm{Na}_{2} \mathrm{CO}_{3}\right.$, Qrec, NZ), potassium iodide (KI, Qrec, NZ), and potassium permanganate $\left(\mathrm{KMnO}_{4}\right.$, Fisher Brand, UK) were used in the chemical analysis. Oxygen gas (170 bar, $\left.8.4 \mathrm{~m}^{3}\right)$ was utilized for the ozonolysis pretreatment. Acetone $\left(\mathrm{CH}_{3} \mathrm{COCH}_{3}\right.$, Merck Brand, Germany) was used to wash the ozonated samples. Distilled water was used for moisturizing the EFB and preparation of solutions. D-Glucose $\left(\mathrm{C}_{6} \mathrm{H}_{12} \mathrm{O}_{6}, \quad\right.$ Qrec, $\left.\quad \mathrm{NZ}\right)$ and D-Cellulose $\left(\mathrm{C}_{6} \mathrm{H}_{10} \mathrm{O}_{5}\right) \mathrm{n}$, Sigma-Aldrich, USA) were adopted as the model compounds for the identification of chemical compositions.

\subsection{Chemical Composition of Empty Fruit Bunch (EFB)}

The cellulose isolation method was conducted to quantify the compositions of cellulose and hemicellulose [22]. Meanwhile, the acid insoluble lignin, acid soluble lignin and ash contents were measured by following the standard laboratory analytical procedure of National Renewable Energy Laboratory (NREL/TP-510-42618).

\subsection{Measurement of Bulk Density and Void Fraction}

The physical properties of untreated EFB in terms of bulk density and void fraction were de- termined according to our previous work [6]. The effect of various moisture contents $(20 \%$, $30 \%$, and $40 \%)$ and different particle sizes $(0.3$ $\mathrm{mm}$ and $0.5 \mathrm{~mm}$ ) on the physical properties were evaluated. The moisture content was measured using moisture analyzer (SASTECTM, ST-LSC60 model, Malaysia) [6].

\subsection{Ozonolysis Pretreatment}

EFB ozonolysis pretreatment experiments were conducted using $\mathrm{OzBiONY}{ }^{\circledR}$ pretreatment prototype as shown in Figure 1(a). The piping and instrumentation diagram (P\&ID) of the OzBiONY® prototype consists of ozone generator (model LAB 2A, Triogen, Scotland), ozone reactor (ribbon mixer semi-batch reactor, $2.47 \mathrm{~L}$ ), ozone monitor (Eco Sensors, UV106M), and ozone destructor (Figure 1(b)).The ozonolysis pretreatment method was thoroughly described in our previous work [22]. Several steps were slightly adjusted in the current study. $20 \mathrm{~g}$ of moistened EFB was placed inside the ozone reactor with the rotation speed of 60 rpm. After completing the ozonolysis pretreatment, the ozonated EFB was immediately swelled in $300 \mathrm{~mL}$ water-acetone $(270 / 30 \mathrm{~mL}$ $\mathrm{v} / \mathrm{v})$ mixture for $2 \mathrm{~h}$ to suspend the lignin and other impurities. The ozonolysis experiments were repeated for the EFB samples at moisture contents of $20 \%, 30 \%$, and $40 \%$. with different particles sizes $(0.3 \mathrm{~mm}$ and $0.5 \mathrm{~mm})$. The values of ozone inlet concentrations were also var-
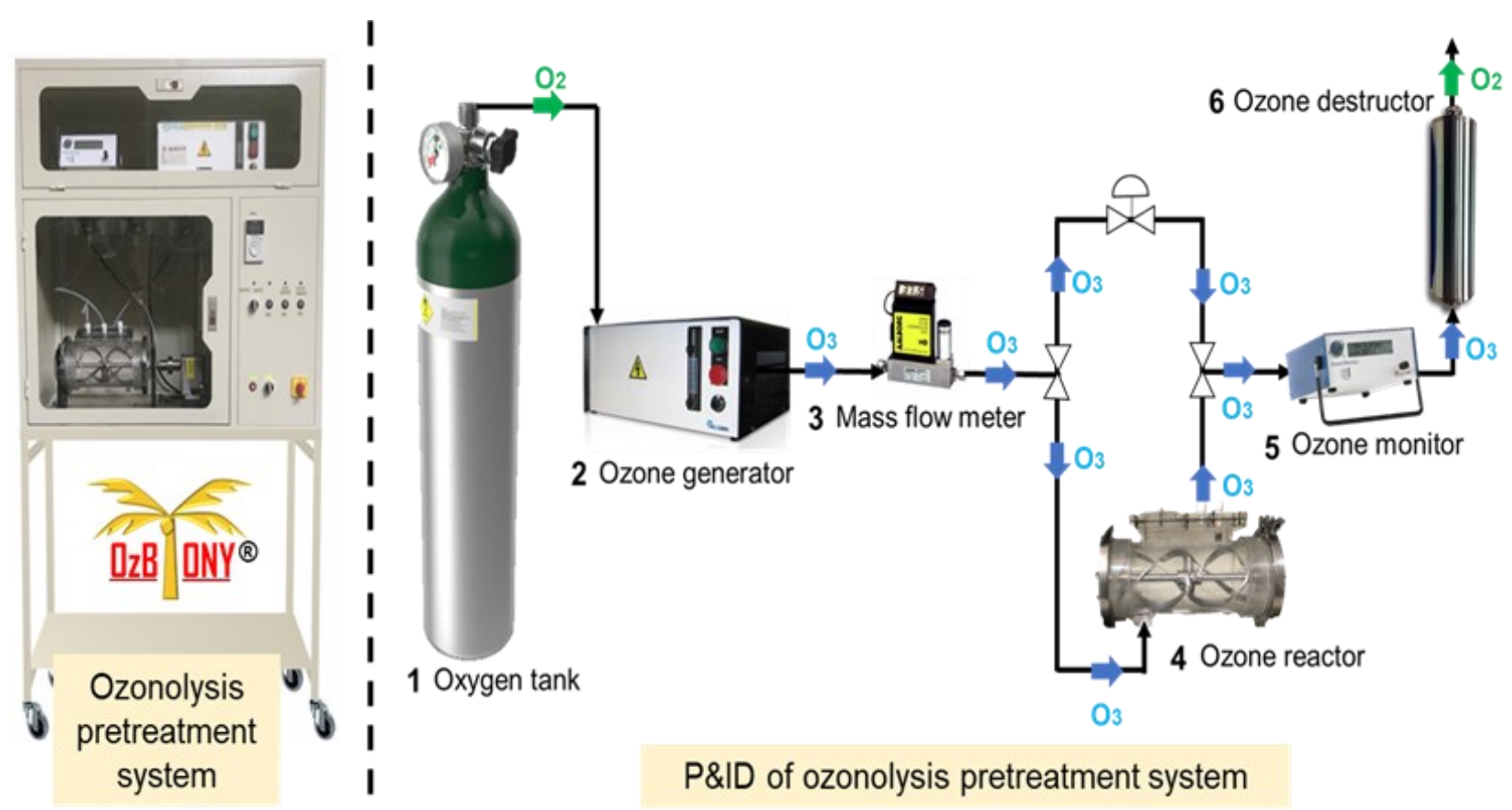

P\&ID of ozonolysis pretreatment system

Figure 1. OzBiONY® pretreatment prototype system (a) and the piping and instrumentation diagram (P\&ID) consists of (1) oxygen tank, (2) ozone generator, (3) mass flow meter, (4) ribbon mixer ozone reactor, (5) ozone monitor, and (6) ozone destructor (b). 
ied at 40,60 and $80 \mathrm{~g} / \mathrm{m}^{3}$ and at different reaction times $(60,90$, and $120 \mathrm{~min})$ to investigate the effectiveness of ozone consumption on lignin degradation.

\subsection{Two-step Acid Hydrolysis}

The detail of two-step acid hydrolysis step was reported elsewhere [22] to determine the amount of TRS yield.

\subsection{Analytical Methods}

\subsubsection{Lignin degradation}

The lignin degradation was determined using Kappa number (K) method calibrated with Klason lignin method [22]. $0.05 \mathrm{~g}$ OTE was mixed with $20 \mathrm{~mL}$ of $\mathrm{H}_{2} \mathrm{SO}_{4}(2 \mathrm{M})$ and $5 \mathrm{~mL}$ of $0.02 \mathrm{M} \mathrm{KMnO}_{4}$. The mixture was stirred at 200 rpm for $5 \mathrm{~min}$ and then filtered. The filtrate was analyzed using UV-vis at $546 \mathrm{~nm}$ and the absorbent reading was recorded as $A_{\text {c. }}$. A blank sample consists mixtures of $\mathrm{KMnO}_{4}$ and $\mathrm{H}_{2} \mathrm{SO}_{4}$ was used as the controller. The absorbent of the blank sample was recorded as $A_{0}$. The lignin degradation of the EFB was calculated based on Eqs. (1)-(3):

$$
\text { Kappa number }, K=100\left[\frac{A_{0}-A_{c}}{A_{0}}\right]
$$

Lignin content $=0.15 \mathrm{~K}$

Lignin degradation $(\% w t)=\frac{\text { Untreated lignin content }- \text { OTE lignin content }}{\text { Untreated lignin content }} \times 100$

\subsubsection{Determination of total reducing sugar} (TRS)

The amount of TRS in the hydrolysis product was determined by biochemistry analyzer (2950D YSI biochemistry analyzer, US). The YSI biochemistry analyzer was calibrated using glucose standard before starting the analysis. About $1.0 \mathrm{~mL}$ of hydrolysate from acid hydrolysis process is added into sample tray and the TRS concentration results was recorded in

Table 1. Chemical composition of EFB.

\begin{tabular}{lc}
\hline Chemical composition (dry basis) & (wt.\%) \\
\hline Cellulose & 53.00 \\
Hemicellulose & 15.44 \\
Acid insoluble lignin (AIL) & 26.67 \\
Acid soluble lignin (ASL) & 0.89 \\
Ash & 4.00 \\
\hline
\end{tabular}

(g/L). The TRS yield in the EFB hydrolysate was computed by Eq. (4) [22]. The TRS yield was multiplied with the total weight of OTE sample to determine the total weight of TRS produced after the pre-treatment. The TRS recovery was then calculated by Eq. (5):

$$
\begin{aligned}
& \text { TRS yield }\left(\frac{\mathrm{g}}{\mathrm{g} \text { OTE }}\right)=\frac{\text { TRS concentration }(\mathrm{mg} / \mathrm{mL}) \times V \times d f \times 0.9}{300 \mathrm{mg} \text { OTE }} \\
& \text { TRS recovery }(\%)=\frac{\text { Total Weight of TRS from OTE }(\mathrm{g})}{\text { Weight of initial } \operatorname{EFB}(\mathrm{g})} \times 100
\end{aligned}
$$

where total volume $(V)$ is equal to $0.087 \mathrm{~L}$, dilution factor $(d f)$ is equal to 1 , and 0.9 is the anhydrous correction for glucose.

\subsection{Characterization of EFB and OTE Samples}

The untreated EFB and OTE samples were dissolved in DMSO and characterized by proton (1H-NMR) in the range of $1-6 \mathrm{ppm}$. The $1 \mathrm{H}-\mathrm{NMR}$ spectra of the products were acquired at $25{ }^{\circ} \mathrm{C}$ using Bruker AV400 high resolution multinuclear NMR spectrometer. The FT-IR spectroscopy (Perkin-Elmer spectrum GX FTIR system, USA) was used to detect major functional group in the extracted cellulose and the absorption mode was recorded in the range of 4000-600 $\mathrm{cm}^{-1}$ using ATR type. The morphology study of untreated EFB and OTE samples was performed using scanning electron microscope, SEM-5410LV with 500X magnification while the elemental composition of the products was detected by using energy disperse $\mathrm{X}$-ray spectrometry (EDX).

\section{Results and Discussion}

The chemical compositions of the EFB are summarized in Table 1 . The results have proved that the EFB is significantly dominated by cellulose components, which are $53 \mathrm{wt} . \%$ is cellulose and 15.44 wt.\% is hemicellulose. The highly cellulose content has made the EFB as an ideal source for cellulose-based natural products. The cellulose component should be exposed to efficiently convert into higher valueadded materials by removing the complex lignin structure which occupies about 27.56 wt.\% of EFB.

\subsection{Effect of EFB Moisture Content on the Physical Properties of EFB}

The physical properties of EFB particles in terms of bulk density and void fraction were studied for particle sizes of $0.3 \mathrm{~mm}$ and $0.5 \mathrm{~mm}$ at different moisture contents; $20 \%, 30 \%$, and $40 \%$. For operational control and design of a re- 
actor containing gas-particle flow, the void fraction and bulk density of solid particles are vital parameters [23]. Void fraction (porosity) is a measure of the void spaces in a solid material which is usually defined as the fraction of the volume of void space available for the flow of fluid over the total volume [24]. In ozonolysis process, the void space is occupied by ozone gas, which flows through the EFB particles. Bulk density is an indicator of particle compaction, which is measured by the mass weight of particles in a unit volume.

The void fraction shown in Figure 2 (a) is decreased and bulk density in Figure 2 (b) is increased as moisture content increased. This proved that the water particles play significant effect towards the change in physical characteristics of EFB. The increase of void volume in the EFB decreases the EFB bulk density. The difference in density, size and shape among EFB particles often leads to particle segregation during flow with large particles rising to the upper surface and small particles percolating down to the base [25].

\subsection{Ozonolysis of EFB}

In ozonolysis of EFB, ozone acts as oxidizing agent and reacts with the surface of EFB to de-

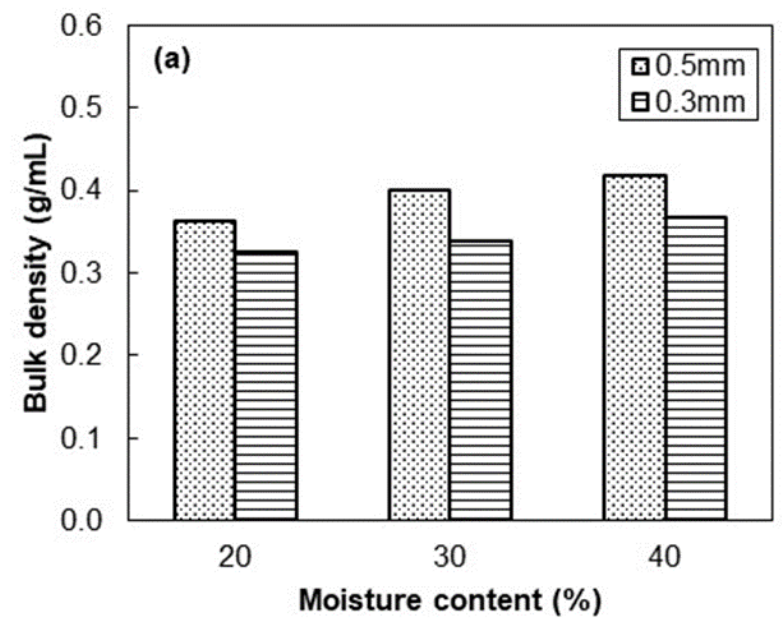

grade lignin without affecting the cellulose component [26]. Based on Criegee mechanism [27], the ozone preferably reacted with aromatic compounds, alkenes, and ketones and break the olefinic double bonds and cycloaddition complexes. Another reaction mode is the ozone insertion into carbon-hydrogen bonds in alcohol-, aldehyde- and ether- type structures. In the case of aryl and alkyl ethers, the reaction results in the cleavage of the ether bond [28].

The subsequent hydrolysis reaction could convert OTE to attain glucose yield as high as $45.09 \%$ [29] which can be used as feedstock for production of 5-hydroxymethylfurfural (5HMF) [30] bioethanol [31], and levulinic acid (LA) [32]. The ozone pretreatment is proven to efficiently reduce the recalcitrance in EFB for the conversion of cellulose and enhancement of sugar release. In hydrolysis reaction, $\beta-1,4$ glycosidic bonds of cellulose chains are broken into glucose molecules by cellulose enzymes via enzymatic hydrolysis [33] or acids via acid hydrolysis [34]. On the other hand, the OTE can also be purified by using acid hydrolysis [35] or sodium hydroxide [36] to be employed as cellulose fiber for box packaging, and raw material for green chemicals production, such as: car-

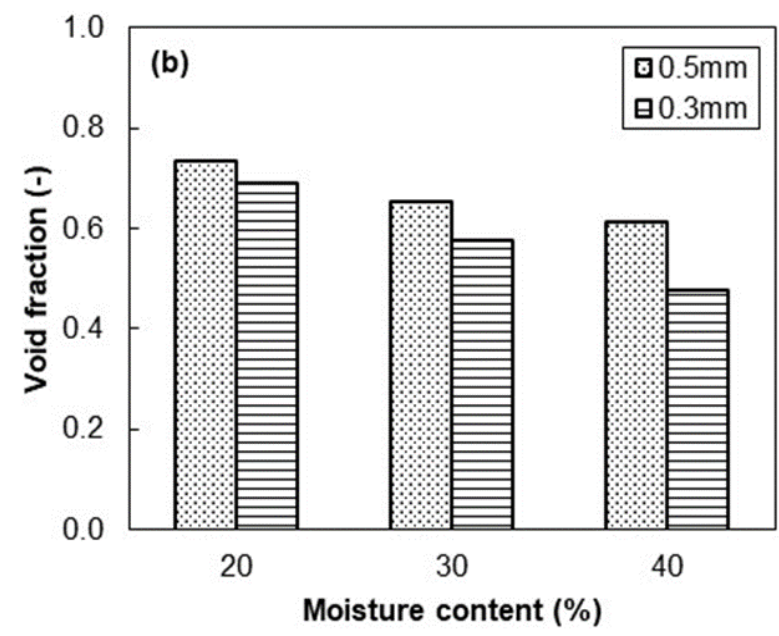

Figure 2. (a) Void fraction and (b) bulk density of EFB over moisture content at $0.3 \mathrm{~mm}$ and $0.5 \mathrm{~mm}$ particle sizes.

Table 2. Process parameters of ozonolysis pretreatment in different types of reactor and biomass.

\begin{tabular}{llcccccc}
\hline Raw material & $\begin{array}{c}\text { Reactor } \\
\text { design }\end{array}$ & $\begin{array}{c}\text { Moisture } \\
\text { content } \\
(\%)\end{array}$ & $\begin{array}{c}\text { Ozone } \\
\text { Concentration } \\
\left(\mathrm{g} / \mathrm{m}^{3}\right)\end{array}$ & $\begin{array}{c}\text { Flow } \\
(\mathrm{L} / \mathrm{h})\end{array}$ & $\begin{array}{c}\text { Time } \\
(\mathrm{h})\end{array}$ & $\begin{array}{c}\text { Delignification } \\
(\%)\end{array}$ & Ref. \\
\hline EFB & Ribbon mixer & 40 & 60 & 2 & 1 & 95.7 & This study \\
Oil Palm Fronds & Semi batch & 30 & $\mathrm{n} . \mathrm{a}$ & 3.6 & 0.5 & 98.7 & {$[49]$} \\
Wheat straw & Batch & 95 & 9.5 & 60 & 5 & 50 & {$[50]$} \\
Poplar sawdust & Fixed-bed & 30 & 0.5 & 60 & 3 & 2 & {$[19]$} \\
Coastal Bermuda grass & Rotatory & 30 & n.a & 60 & 1 & 31 & {$[13]$} \\
Red oak & Cylindrical & 50 & n.a & 30 & 2 & - & {$[51]$} \\
\hline
\end{tabular}


boxymethyl cellulose (CMC), microcrystalline cellulose (MCC), and cellulose nanocrystal (CNC), which are widely used as hydrogels, pickering emulsifier, binders, membranes and polymer coatings [35]. The effect of process parameters and reactor design is discussed in this section.

\subsubsection{Effect of reactor design}

Various factors affect the effectiveness of ozonolysis process as describe in previous literature including the interaction between ozone with substrate, reactor design and reaction parameters. The optimum process parameters for ozonolysis process such as moisture content, reaction time and ozone flowrate are compared with the previous studies as shown in Table 2 . The results show the highest delignification of biomass was obtained using ribbon mixer reactor design. The radial mixing generated by the ribbon mixer helps to increase reaction rate and interfacial contact of the biomass with ozone in order to favor the oxidation reaction. The pre-treatment of biomass in general and EFB in particular becomes more effective with
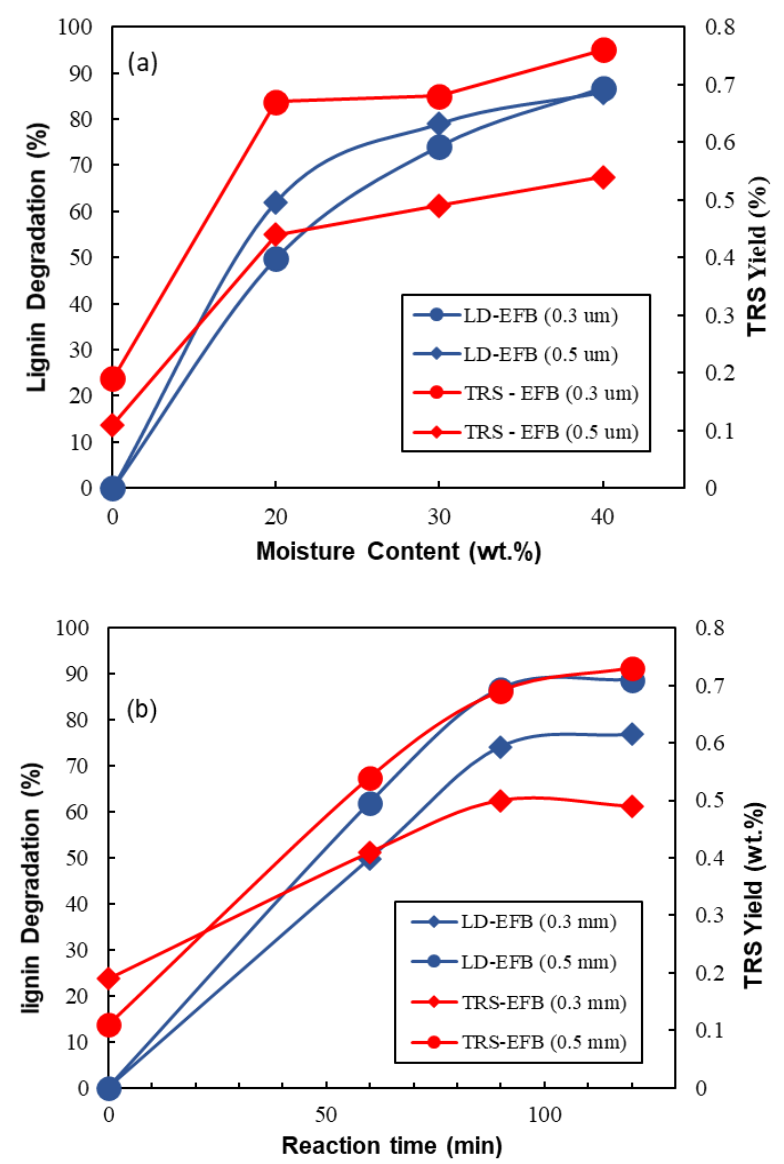

higher lignin degradation rate and increment of the TRS yield.

3.2.2 Effect of process parameter; moisture content, reaction time and ozone concentration

Moisture content is arguably the most important process parameter for ozonolysis reactor to occur, since its form mass transport medium and influence the generation of radicals. As mentioned in previous studies, the optimal moisture content is in the range of 10 to 50 wt.\% for ozonolysis of oil palm biomass [37,22], hence the ribbon mixer reactor used in this study helps to homogenous ozone concentration with moisture content in the biomass. From Figure 3 (a), it shows that the lignin degradation and TRS yield increase with the rise of moisture content. At low moisture content, ozone mass transfer was limited since the ozone was beginning to react with bounded water. At 40 wt.\%, the EFB $0.3 \mathrm{~mm}$ and EFB 0.5 $\mathrm{mm}$ obtained high lignin degradation of $86.8 \%$ and $95.6 \%$ with highest TRS yield of 0.76 wt.\% and 0.54 wt.\%, respectively. However, if the water content is excessive, the water particles will block the biomass pore with the formation of thick film which favors larger residence time of ozone, thus enhances the decomposition of hydroxyl radical. Hence, moisture content more than $40 \mathrm{wt} . \%$ is not favorable since the lignin will not properly degraded [38].

The effect of EFB ozonolysis with reaction time is shown in Figure 3 (b), where the results shown concur with previous study involving other types of biomass. The delignification of cereal straws [21] was rapidly increased in 60 min reaction time, and reduced within $90 \mathrm{~min}$ due to acid insoluble lignin (AIL) degradation. Wan et al. [22] also discovered the oil palm

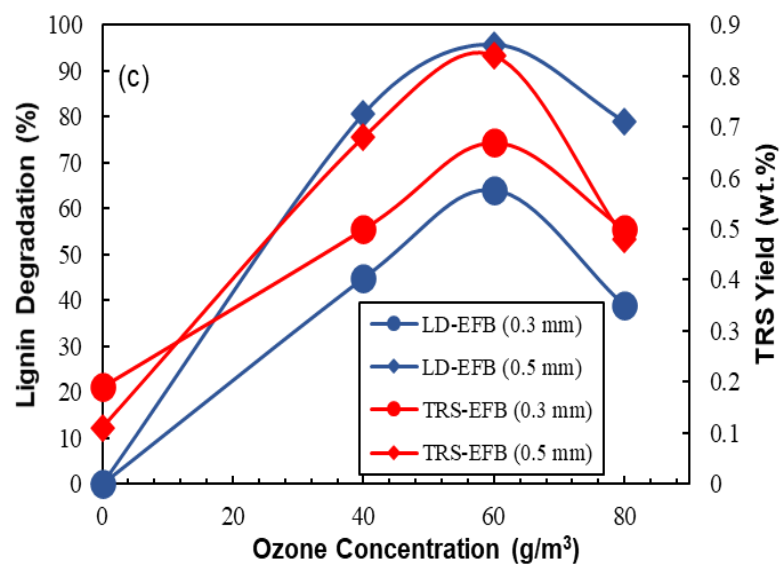

Figure 3. Effect of ozonolysis of EFB over (a) moisture content, (b) reaction time, (c) ozone concentration, (d) ozone consumption. 
fronds reaction with ozone decrease the lignin degradation after reaction time more than 60 min since the ozone could react with hemicellulose on the exposed surface after the lignin layer was degraded.

It is clearly observed that the delignification has three visible stages [39]: (1) Initial, (2) Bulk, and (3) Residual. At the beginning of the reaction time, the delignification occurred very fast. In the initial phase, around $20 \%$ of lignin degraded mainly due to the reaction of phenolic and carbonyl structures. The bulk phase is up to $90 \mathrm{~min}$, where the highest delignification obtained for EFB $0.3 \mathrm{~mm}$ and EFB $0.5 \mathrm{~mm}$ were $74.1 \%$ and $86.8 \%$, respectively. The TRS yield also increased in relation of more surface area of cellulose is exposed while lignin bonds break down. After $90 \mathrm{~min}$, the retarded delignification is established in the residual phase due to very small amount of lignin is dissolved. The residual lignin remains intact even after a prolonged ozone exposure because of three main reasons: (1) The presence of alkaline-stable native lignin structure, (2) The presence of alkaline-stable covalent linkages between lignin and carbohydrates and, (3) The occurrence of condensation reactions in lignin.

Figure 3 (c) shows the effect of ozonolysis of EFB with ozone concentration. The lignin degradation and TRS yield are increased until 60 $\mathrm{g} / \mathrm{m}^{3}$ and started to decrease afterwards. High lignin degradation of $95.7 \%$ and $64.1 \%$ was obtained for EFB $0.3 \mathrm{~mm}$ and EFB $0.5 \mathrm{~mm}$, respectively, while high TRS yield of 0.84 and 0.67 was obtained for EFB $0.3 \mathrm{~mm}$ and EFB 0.5 $\mathrm{mm}$, respectively. This is due to high inhibitory compounds were generated by degraded sugar with low molecular lignin compounds at higher ozone concentration [40]. The increase in TRS yield was attributed to the disrupted lignin structures, which allowed cellulose to be more accessible for subsequent hydrolysis steps.

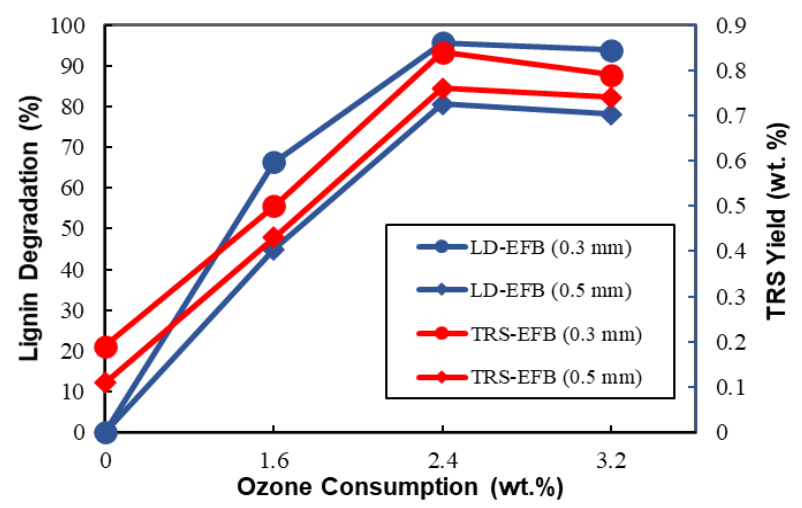

Figure 4. Effect of ozone consumption on TRS yield and lignin degradation.

\subsubsection{Effect of ozone consumption}

Previous studies by Wan et al. [22] and Schultz-Jensen et al. [26] have discussed the increase in cellulose component and decrease in lignin in ozonated biomass. However, although the TRS yield in hydrolysate was increased, the TRS yield in OTE might not be large due to excessive ozonation which could lead to sugar losses and low OTE weight after the pretreatment.

The ozonolysis pre-treatment is not economically feasible for full scale industrial implementation due to high cost of ozone production and maintenance, hence minimal ozone consumption is required to increase the feasibility of ozone pretreatment. As stated by Travaini et al. [41], ozone consumption can be defined as the amount of ozone consumed per gram biomass. The relationship between ozone consumption with lignin degradation of EFB are shown in Figure 4. The ozone consumption is directly dependent on reaction time, ozone concentration and inlet gas flow [42]. The glucose yield in hydrolysate increased rapidly with ozone consumption, which attributes to the sugar release at higher ozone concentration and ozonation time. However, lignin degradation and glucose yield slightly decreased and became constant after 3 wt.\% ozone consumption as shown in Figure 4. This could be attributed to the delignification process being suppressed since the pores at the outermost layer gradually became impermeable during ozone-lignin reactions thus, preventing the ozone from diffusing into the lignin interior [43]. The formation of impermeable barrier limited the ozone mass transfer to complete the degradation of lignin. The loss of moisture due to ozone-lignin reaction could also be another reason for reducing delignification and the presence of residual lignin. Similar trends have been found in previous reports on the delignification of sweet sorghum bagasse obtained by alkali pre-treatment [44] and sugarcane bagasse obtained by chemical pre-treatment [45]. Excessive ozone consumption could lead the formation of inhibitory compounds by sugar degradation and expensive cost operation, hence operation above $3 \mathrm{wt} . \%$ ozone consumption is not favorable.

3.3 Characteristic and Structural Changes on Ozone Pre-treated Lignocellulosic Biomass

\subsubsection{NMR Characterization}

The chemical characterization of ozonated products are shown in Figure 5. It distin- 
(a)

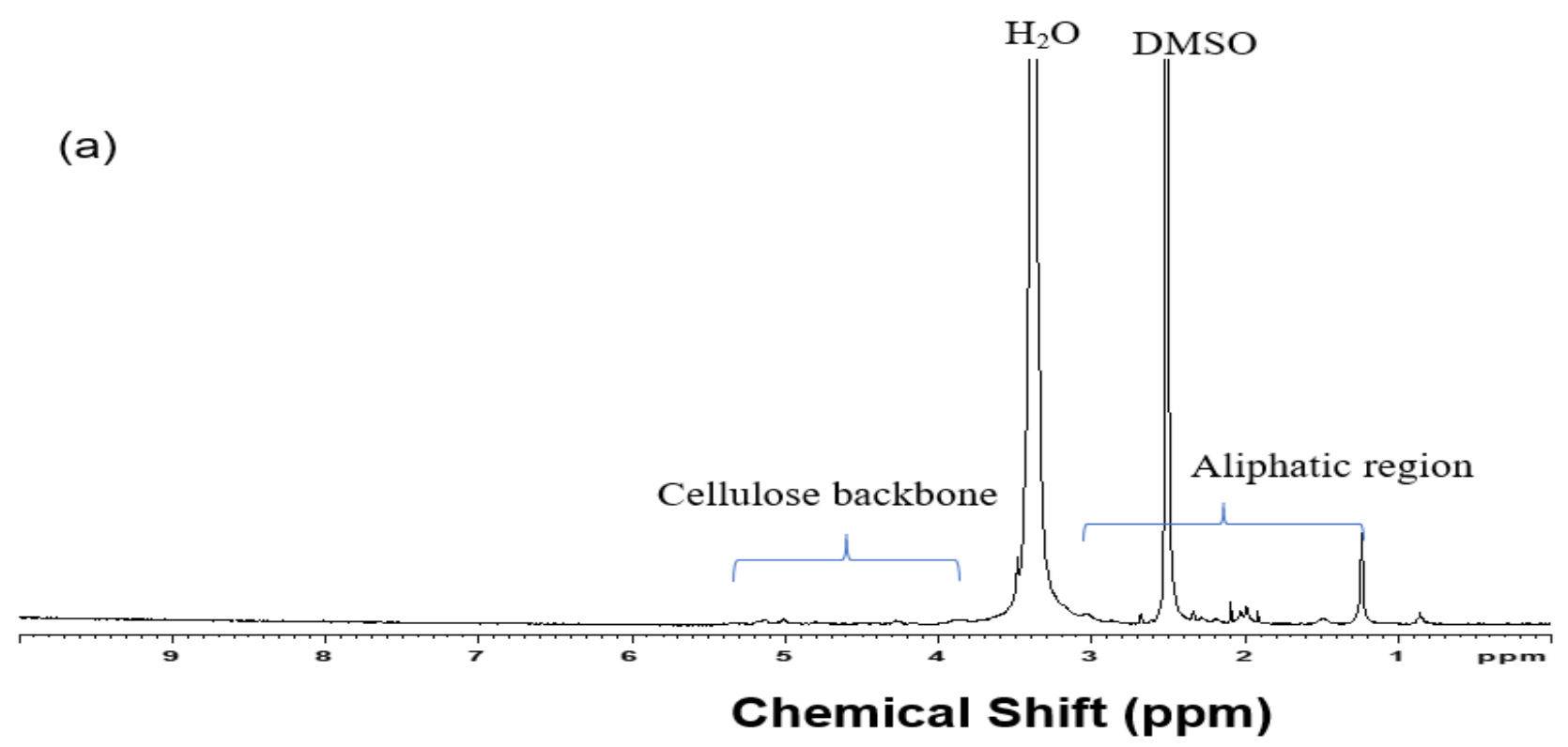

(b)

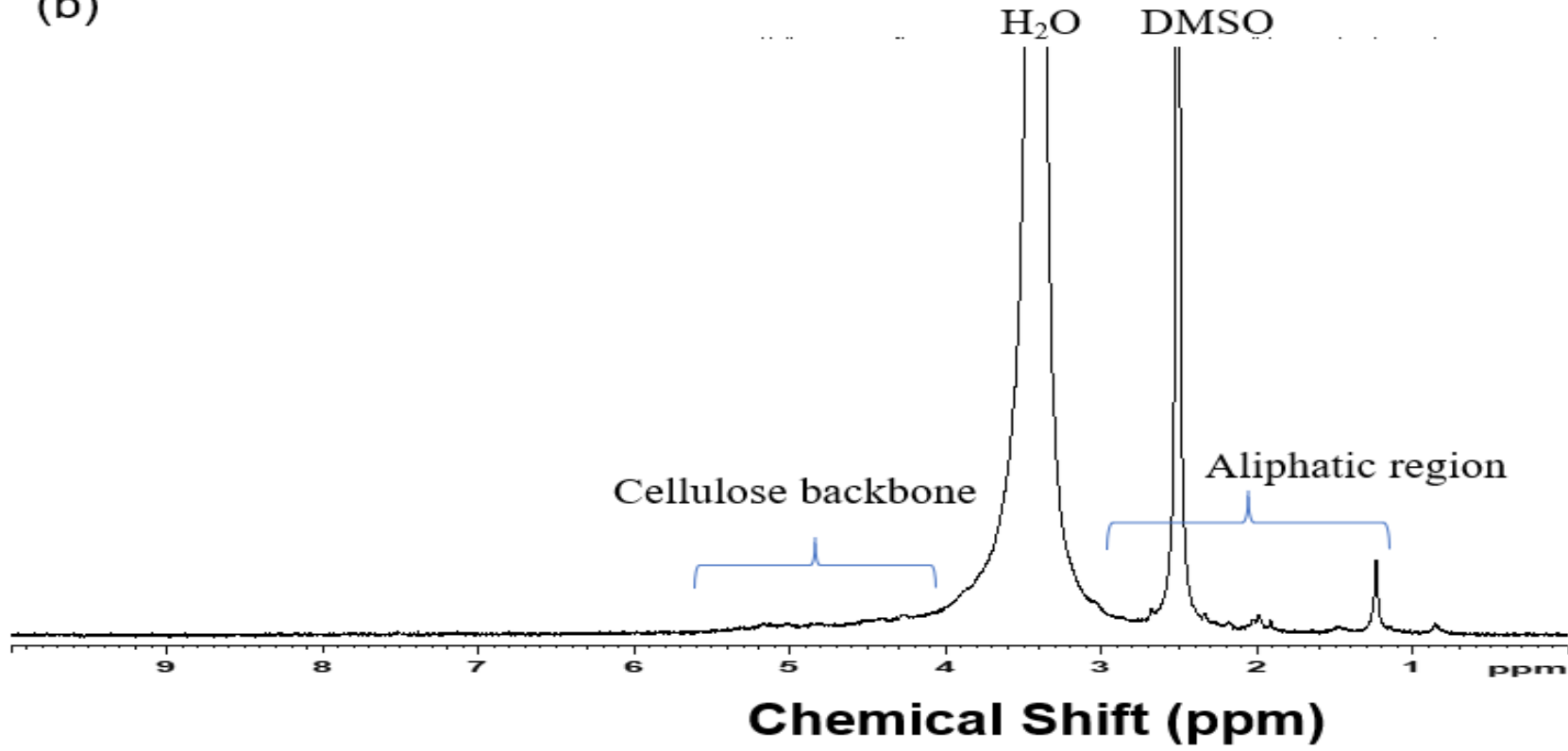

(c)

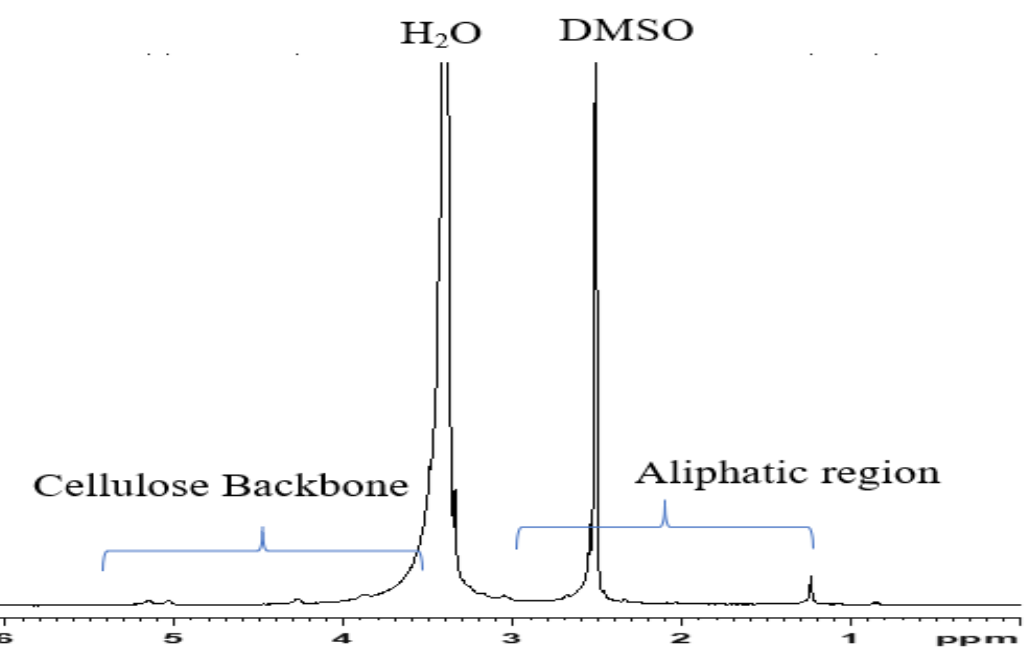

\section{Chemical Shift (ppm)}

Figure 5. NMR spectra of ozone treated EFB at (a) $40 \mathrm{~g} / \mathrm{m}^{3}$, (b) OTE $60 \mathrm{~g} / \mathrm{m}^{3}$ and (c) $80 \mathrm{~g} / \mathrm{m}^{3}$. 
guishes the distribution of the proton aliphatic region shift values at 1 to $3 \mathrm{ppm}$, indicating ozone has a prominent effect on the biomass component. These results are also supported by other researchers [46,41], stating that aromatic component of lignin was very susceptible to ozone reactions. The signal corresponding to cellulose backbone occurred at 4 to $5.5 \mathrm{ppm}$ in the ozonated samples as ozone concentration increased.

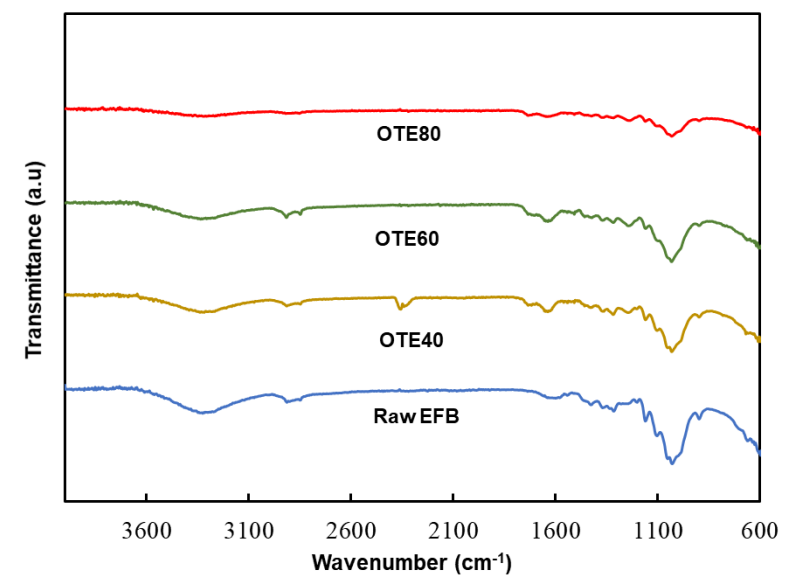

Figure 6. ATR-FTIR spectra of EFB raw and ozonated sample.

\subsubsection{ATR FT-IR Characterization}

Based on the Fourier transform infrared (FT-IR) analysis in Figure 6, the destruction of aromatic rings and ketones and aldehydes formation as ozone concentration increases up to $60 \mathrm{~g} / \mathrm{m}^{3}$ are evident in the OTE samples. Higher ozone concentrations promote the production of inhibitory compounds by sugar degradation and by reaction with low molecular lignin compounds. This is due to the partial oxidation reaction between hemicellulose and lignin. According to Criegee's mechanism, ozone attacks lignin double bonds and leads to formation of carbonyl compounds and aliphatic carbon acids [24]. Besides, the peak intensity was significantly reduced between $1458 \mathrm{~cm}^{-1}$ which is attributed to the aromatic stretching vibration of lignin degradation [47]. The decrease in the peak intensity at the absorption peak of 1750 $\mathrm{cm}^{-1}$ and $1025 \mathrm{~cm}^{-1}$ could be attributed to the disappearance of ester $\mathrm{C}=\mathrm{O}$ stretching and ether symmetric stretching.

\subsubsection{SEM Characterization}

The SEM images of raw EFB and ozonized EFB samples are exhibited in Figure 7. The raw EFB tends to appear smoother than the
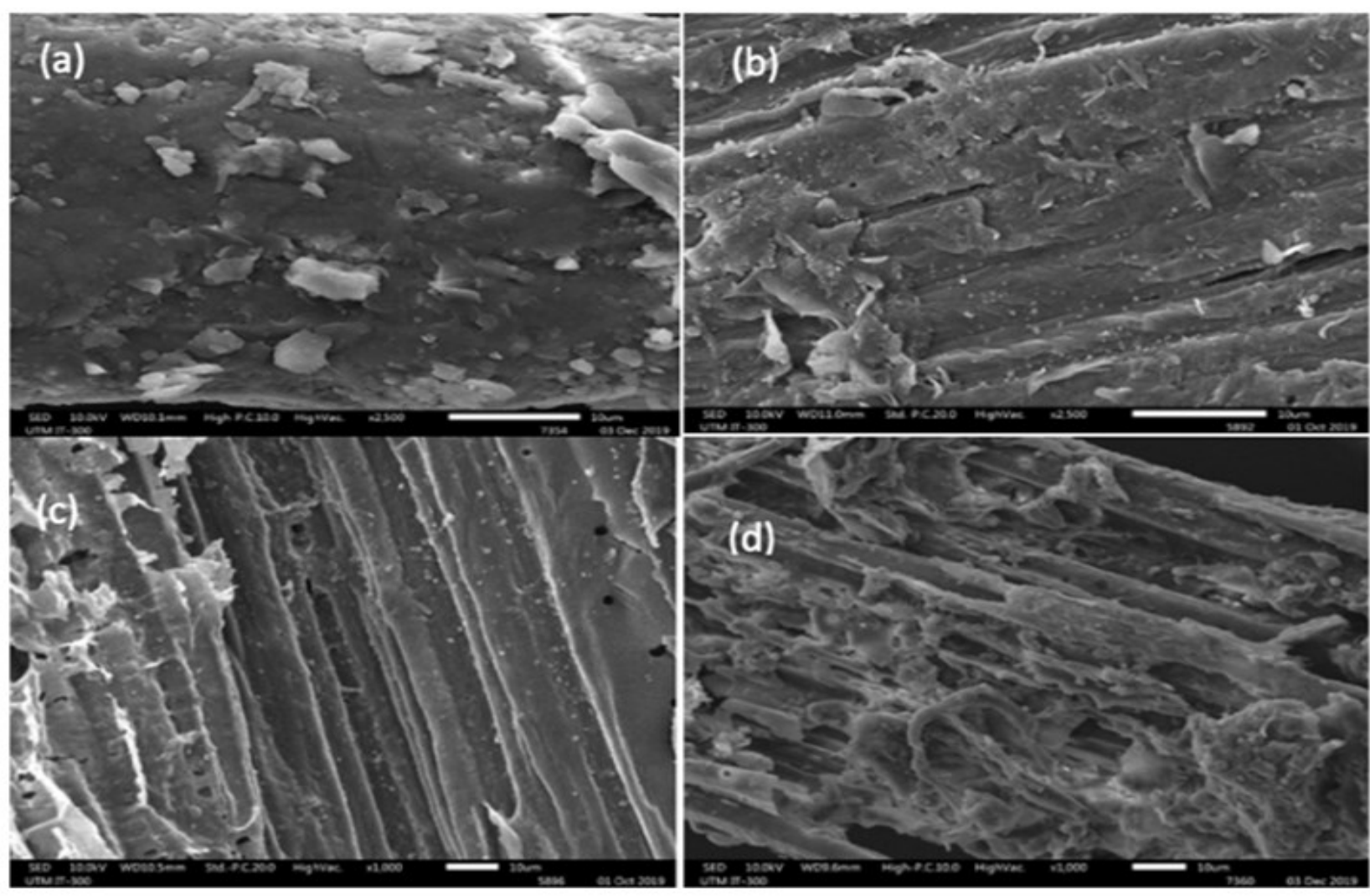

Figure 7. SEM images of EFB at 500X magnification; (a) EFB raw (b) OTE $40 \mathrm{~g} / \mathrm{m}^{3}$, and (c) OTE 60 $\mathrm{g} / \mathrm{m}^{3}(\mathrm{~d})$ OTE $80 \mathrm{~g} / \mathrm{m}^{3}$. 
surfaces of OTE samples. These morphological changes in OTE samples is due to the decomposition of lignin at the surface of EFB because of ozone gas exposure. Based on the figure, the ozone concentration gives significant effect on the biomass surface as the surface becomes rougher. The ozone gas interaction with OTE surface causes the lignin linkage breakdown and exposes the crystalline portions of the cellulose [48].

The surface morphology changes of the OTE samples are parallel with the FTIR analysis discussion which are associated with the changes in functional group and bonds due to the destruction of lignin. Besides, the wax at the surface of OTE was reduced as ozone concentration increased [48]. Based on Figure 7 (c,d), SEM images of ozonated EFB reveal the formation of porous structures, due to the dis-
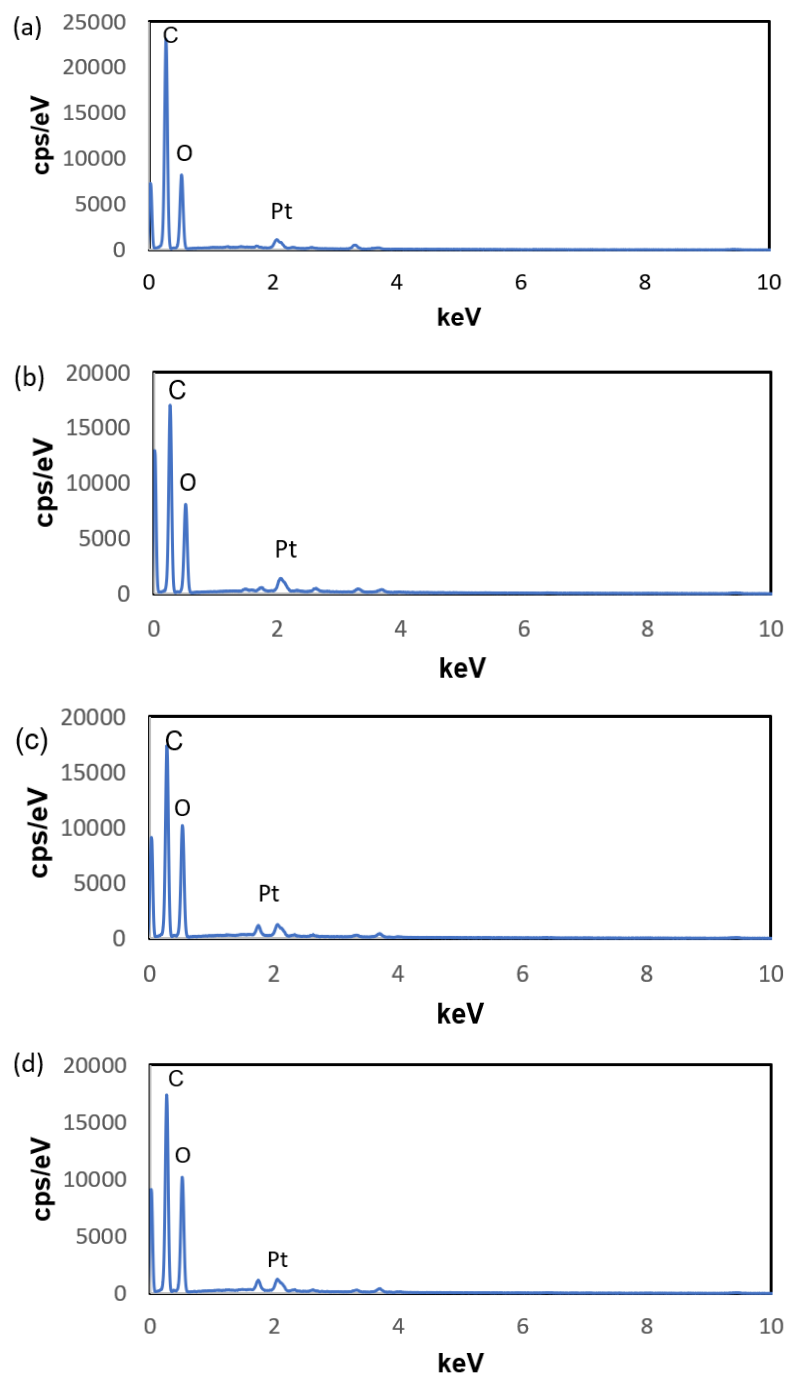

Figure 8. EDX elemental composition data of (a) EFB raw, (b) OTE at $40 \mathrm{~g} / \mathrm{m}^{3}$, (c) $60 \mathrm{~g} / \mathrm{m}^{3}$, and (d) $80 \mathrm{~g} / \mathrm{m}^{3}$. ruption of physical structures. The structural changes are attributed to the lignin degradation and hemicellulose solubilization [46].

\subsubsection{Energy dispersive X-ray (EDX)}

The EDX analysis in Figure 8 shows the elemental ratio for raw EFB and OTE at 40,60, and $80 \mathrm{~g} / \mathrm{m}^{3}$. Based on the figure, the carbon ratio of raw EFB is higher compared to ozone treated EFB due to ozone gas oxidized and decomposed lignin by breaking the lignin bonds. Thus, the carbon content of EFB decreases. The ozonated EFB increases the oxygen content of the sample by converting the lignin component into hydroxyl, carbonyl, and carboxyl groups. In addition, other elements, such as: $\mathrm{K}, \mathrm{Ca}$, and $\mathrm{Si}$ which are known as major elements in ash composition, also decrease compared to the raw EFB due to breaking down of structural surface of EFB diminishing these elements owing to the ozonation process.

The OTE samples and raw EFB were analyzed using EDX analysis for its ratio of oxygen-to-carbon $(\mathrm{O} / \mathrm{C})$ as shown in Figure 9. The $\mathrm{O} / \mathrm{C}$ ratio increased as ozone concentration increased from 0.32 to 0.61 due to the formation of atomic oxygen from ionized air with the surface of OTE. The increase in O/C ratios obtained concurs with the study reported by Klarhöfer et al. [45], where it stated that the decomposition of lignin and oxidation reaction led to formation of hydroxyl, carboxyl and carbonyl groups [48].

\section{Conclusion}

This study indicates that reaction parameters have significant effect on the chemical and structural changes and TRS recovery in ozonolysis of EFB. The additional mixing application in the reactor enhances the interaction be-

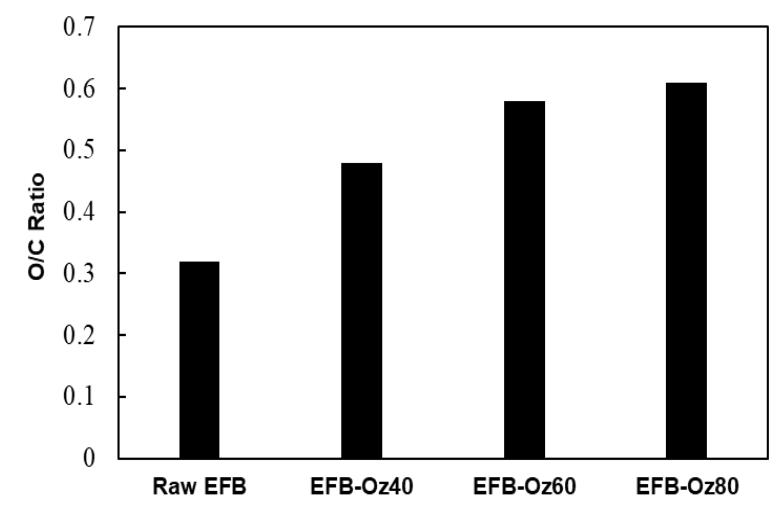

Figure 9. O/C ratio of (a) EFB raw, (b) OTE at $40 \mathrm{~g} / \mathrm{m}^{3}$, (c) $60 \mathrm{~g} / \mathrm{m}^{3}$, and (d) $80 \mathrm{~g} / \mathrm{m}^{3}$. 
tween EFB particles with ozone, thus increases lignin degradation and TRS yield. The highest delignification obtained was 95.7 wt.\% and TRS yield was enhanced to $84.9 \%$ at moisture content of 40 wt.\% with $60 \mathrm{~g} / \mathrm{m}^{3}$ ozone concentration within 1-hour of reaction time. Both NMR and FTIR spectra confer major peaks attributing to lignin disappearance and higher lignin degradation can be achieved with ozonolysis. The results infer that the ozonolysis pretreatment is able to modify the surface properties of EFB, and that ozonolysis pre-treatment could improve the glucose recovery for downstream bio-based conversion. The results also provide better understanding of ozonolysis of EFB for future up-scaling application and development.

\section{Acknowledgement}

The authors would like to express their sincere gratitude to Universiti Teknologi Malaysia (UTM) for the financial assistance under grant PRGS-ICC (Vote 4J325), Professional Development Research University Post-Doctoral Fellowship (Vote 04E18) and FRGS-MRSA (Vote 4F988).

\section{References}

[1] Anastassiadis, S. (2016). Carbon Sources For Biomass, Food, Fossils, Biofuels and Biotechnology - Review Article. World Journal of Biotechnology, 1, 1-32.

[2] Adarme, O.F.H., Baêta, B.E.L., Lima, D.R.S., Gurgel, L.V.A., de Aquino, S.F. (2017). Methane and hydrogen production from anaerobic digestion of soluble fraction obtained by sugarcane bagasse ozonation. Industrial Crops and Products, 109, 288-299. DOI: 10.1016/j.indcrop.2017.08.040

[3] Kumar, D., Singh, B., Korstad, J. (2017). Utilization of lignocellulosic biomass by oleaginous yeast and bacteria for production of biodiesel and renewable diesel. Renewable and Sustainable Energy Reviews, 73, 654-671. DOI: 10.1016/j.rser.2017.01.022

[4] Ghimire, A., Trably, E., Frunzo, L., Pirozzi, F., Lens, P.N.L., Esposito, G., Cazier, E.A., Escudié, R. (2018). Effect of total solids content on biohydrogen production and lactic acid accumulation during dark fermentation of organic waste biomass. Bioresource Technology, $248, \quad 180-186 . \quad$ D O I : 10.1016/j.biortech.2017.07.062.

[5] Otti, V., Ifeanyichukwu, H., Nwaorum, F., Ogbuagu, F. (2014). Sustainable oil palm waste management in engineering development. Civil and Environmental Research, 6, 121-125.
[6] Shamjuddin, A., Rasid, N.S.A., Raissa, M.M.M., Omar, W.N.W., Amin, N.A.S. (2021). Modelling of ozone multiphase flow behaviour in an ozonolysis reactor for pretreatment of oil palm waste. IOP: Materials Science and Engineering, 1053, 12109. DOI: 10.1088/1757899X/1053/1/012109.

[7] Rasid, N.S.A., Asadullah, M., Malek, N.H., Amin, N.A.S. (2020). Fast pyrolysis of oil palm empty fruit bunch in an auger reactor: bio-oil composition and characteristics. IOP Conference Series: Materials Science and Engineering, 736, 032021. DOI: 10.1088/1757899x/736/3/032021.

[8] Zoghlami, A., Paës, G. (2019). Lignocellulosic Biomass: Understanding Recalcitrance and Predicting Hydrolysis. Frontiers in Chemistry, 7, 874. DOI: 10.3389/fchem.2019.00874.

[9] Rasid, N.S.A., Zainol, M.M., Amin, N.A.S. (2020). 14 - Pretreatment of agroindustry waste by ozonolysis for synthesis of biorefinery products, in: R.P. Kumar, E. Gnansounou, J.K. Raman, G. Baskar (Eds.) Refining Biomass Residues for Sustainable Energy and Bioproducts. Academic Press2020, pp. 303336. DOI: 10.1016/B978-0-12-8189962.00014-4.

[10] Domański, J., Marchut-Mikołajczyk, O., Polewczyk, A., Januszewicz, B. (2017). Ozonolysis of straw from Secale cereale L. for anaerobic digestion. Bioresource Technology, $245, \quad 394-400$ D O I : 10.1016/j.biortech.2017.08.090

[11] Daouk, E., Van de Steene, L., Paviet, F., Martin, E., Valette, J., Salvador, S. (2017). Oxidative pyrolysis of wood chips and of wood pellets in a downdraft continuous fixed bed reactor. Fuel, 196, 408-418. DOI: 10.1016/j.fuel.2017.02.012

[12] Solomon, R., Miron, J., Rubinstein, A., BenGhedalia, D. (1992). Ozone-treated cotton stalks as a component of a ration for growing lambs. Animal Feed Science and Technology, 37, 185-192. DOI: 10.1016/03778401(92)90002-N

[13] Lee, J., Jameel, H., Venditti, R. (2010). Effect of ozone and autohydrolysis pretreatments on enzymatic digestibility of coastal bermuda grass. Bioresources, 5(2), 1084-1101.

[14] Arvaniti, E., Jerre, A.B.B., Schmidt, J.E. (2012). Wet oxidation pretreatment of rape straw for ethanol production. Biomass and Bioenergy, 39, 94-105. DOI: 10.1016/j.biombioe.2011.12.040

[15] Falconí, J.H.H., Soares, J., Rocha, D.N., Vaz, M.G.M.V., Martins, M.A. (2021). Strain screening and ozone pretreatment for algae farming in wastewaters from sugarcane etha- 
nol biorefinery. Journal of Cleaner Production, $\quad 282, \quad 124522$. D O I : 10.1016/j.jclepro.2020.124522

[16] Pisutpaisal, N., Tanikkul, P., Phoochinda, W. (2014). Improvement of Mesophilic Biohydrogen Production from Palm Oil Mill Effluent Using Ozonation Process. Energy Procedia, $50, \quad 723-728$. D O I : 10.1016/j.egypro.2014.06.089

[17] Cardeña, R., Moreno, G., Bakonyi, P., Buitrón, G. (2017). Enhancement of methane production from various microalgae cultures via novel ozonation pretreatment. Chemical Engineering Journal, 307, 948-954. DOI: 10.1016/j.cej.2016.09.016

[18] Bar Oz, Y., Mamane, H., Menashe, O., CohenYaniv, V., Kumar, R., Iasur Kruh, L., Kurzbaum, E. (2018). Treatment of olive mill wastewater using ozonation followed by an encapsulated acclimated biomass. Journal of Environmental Chemical Engineering, 6, 5014-5023. DOI: 10.1016/j.jece.2018.07.003

[19] Vidal, P.F., Molinier, J. (1988). Ozonolysis of lignin - Improvement of in vitro digestibility of poplar sawdust. Biomass, 16, 1-17. DOI: 10.1016/0144-4565(88)90012-1

[20] Cesaro, A., Belgiorno, V. (2013). Sonolysis and ozonation as pretreatment for anaerobic digestion of solid organic waste. Ultrasonics Sonochemistry, 20, 931-936. DOI: 10.1016/j.ultsonch.2012.10.017

[21] García-Cubero, M.T., Palacín, L.G., GonzálezBenito, G., Bolado, S., Lucas, S., Coca, M. (2012). An analysis of lignin removal in a fixed bed reactor by reaction of cereal straws with ozone. Bioresource Technology, 107, 229234. DOI: 10.1016/j.biortech.2011.12.010

[22] Wan Omar, W.N.N., Amin, N.A.S. (2016). Multi response optimization of oil palm frond pretreatment by ozonolysis. Industrial Crops and Products, 85, 389-402. DOI: 10.1016/j.indcrop.2016.01.027

[23] Agu, C.E., Pfeifer, C., Moldestad, B.M.E. (2019). Prediction of void fraction and minimum fluidization velocity of a binary mixture of particles: Bed material and fuel particles. Powder Technology, 349, 99-107 DOI: 10.1016/j.powtec.2019.03.027

[24] Gui, N., Jiang, S., Tu, J., Yang, X. (2019). Gas-Particle and Granular Flow Systems: Coupled Numerical Methods and Applications. Elsevier.

[25] Gray, J.M.N.T. (2018). Particle Segregation in Dense Granular Flows. Annual Review of Fluid Mechanics, 50, 407-433. DOI: 10.1146/annurev-fluid-122316-045201
[26] Schultz-Jensen, N., Kádár, Z., Thomsen, A.B., Bindslev, H., Leipold, F. (2011). PlasmaAssisted Pretreatment of Wheat Straw for Ethanol Production. Applied Biochemistry and Biotechnology, 165, 1010-1023. DOI: 10.1007/s12010-011-9316-x

[27] Criegee, R. (1975). Mechanism of Ozonolysis. Angewandte Chemie International Edition in English, 14, 745-752. DOI: 10.1002/anie. 197507451

[28] Travaini, R., Martín-Juárez, J., LorenzoHernando, A., Bolado-Rodríguez, S. (2016). Ozonolysis: An advantageous pretreatment for lignocellulosic biomass revisited. Bioresource Technology, 199, 2-12. DOI: 10.1016/j.biortech.2015.08.143

[29] Osuna-Laveaga, D.R., García-Depraect, O., Vallejo-Rodríguez, R., López-López, A., LeónBecerril, E. (2020). Integrated OzonationEnzymatic Hydrolysis Pretreatment of Sugarcane Bagasse: Enhancement of Sugars Released to Expended Ozone Ratio. Processes, 8(10), 1274. DOI: 10.3390/pr8101274

[30] Pham, S.T., Nguyen, M.B., Le, G.H., Pham, T.T., Quan, T.T., Nguyen, T.D., Son, T.L., Vu, T.A. (2019). Cellulose conversion to 5 hydroxymethyl furfural (5-HMF) using Alincorporated SBA-15 as highly efficient catalyst. Journal of Chemistry, 2019, 5785621. DOI: $10.1155 / 2019 / 5785621$

[31] Vasić, K., Knez, Ž., Leitgeb, M. (2021). Bioethanol Production by Enzymatic Hydrolysis from Different Lignocellulosic Sources. Molecules, $\quad 26$ ( 3 ), $\quad 753$. D O I : 10.3390/molecules26030753

[32] Pyo, S.-H., Glaser, S.J., Rehnberg, N., HattiKaul, R. (2020). Clean Production of Levulinic Acid from Fructose and Glucose in Salt Water by Heterogeneous Catalytic Dehydration. ACS Omega, 5, 14275-14282. DOI: 10.1021/acsomega.9b04406

[33] Rastegari, A.A. (2018). Chapter 8 - Molecular Mechanism of Cellulase Production Systems in Penicillium, New and Future Developments in Microbial Biotechnology and Bioengineering, Elsevier, 153-166. DOI: 10.1016/B978-0444-63505-1.00008-7

[34] Kong-Win Chang, J., Duret, X., Berberi, V., Zahedi-Niaki, H., Lavoie, J.M. (2018). Twostep thermochemical cellulose hydrolysis with partial neutralization for glucose production. Frontiers in Chemistry, 6, 117. DOI: 10.3389/fchem.2018.00117

[35] Padzil, F.N.M., Lee, S.H., Ainun, Z.M.A.A., Lee, C.H., Abdullah, L.C. (2020). Potential of oil palm empty fruit bunch resources in nanocellulose hydrogel production for versatile applications: A review. Materials, 13(5), 1245. DOI: $10.3390 / \mathrm{ma} 13051245$ 
[36] Isroi, I., Cifriadi, A. (2018). Oxidation of Cellulose from Oil Palm Empty Fruit Bunch Using Hydrogen Peroxide in Alkaline Condition. Jurnal Selulosa, 8(02), 51-60. DOI: 10.25269/jsel.v7i02.233

[37] Travaini, R., Barrado, E., Bolado-Rodríguez, S. (2016). Effect of ozonolysis pretreatment parameters on the sugar release, ozone consumption and ethanol production from sugarcane bagasse. Bioresource Technology, 214, 150-158. DOI: 10.1016/j.biortech.2016.04.102

[38] Souza-Corrêa, J.A., Oliveira, C., Nascimento, V.M., Wolf, L.D., Gómez, E.O., Rocha, G.J.M., Amorim, J. (2014). Atmospheric Pressure Plasma Pretreatment of Sugarcane Bagasse: the Influence of Biomass Particle Size in the Ozonation Process. Applied Biochemistry and Biotechnology, 172, 1663-1672. DOI: 10.1007/s12010-013-0609-0

[39] Fearon, O., Kuitunen, S., Ruuttunen, K., Alopaeus, V., Vuorinen, T. (2020). Detailed Modeling of Kraft Pulping Chemistry. Delignification. Industrial \& Engineering Chemistry Research, 59, 12977-12985. DOI: 10.1021/acs.iecr.0c02110

[40] Zhao, Z., Zhang, J., Li, Y., Li, F., Liu, P. (2021). Effects and Mechanisms of Alkali Recycling and Ozone Recycling on Enzymatic Conversion in Alkali Combined with Ozone Pretreatment of Corn Stover. Applied Biochemistry and Biotechnology, 193, 281-295. DOI: $10.1007 / \mathrm{s} 12010-020-03425-4$

[41] Travaini, R., Barrado, E., Bolado, S. (2015). Sugarcane bagasse ozonolysis pretreatment Hydrolysates fermentation by brewer's yeast Saccharomyces cerevisiae. Journal of Biotechno $\log y, \quad 208, \quad \mathrm{~S} 118$. D O I : 10.1016/j.jbiotec.2015.06.373

[42] Li, C., Wang, L., Chen, Z., Li, Y., Wang, R., Luo, X., Cai, G., Li, Y., Yu, Q., Lu, J. (2015). Ozonolysis pretreatment of maize stover: The interactive effect of sample particle size and moisture on ozonolysis process. Bioresource Technology, 183, 240-247. DOI: 10.1016/j.biortech.2015.01.042

[43] Bhattarai, S., Bottenus, D., Ivory, C.F., Gao, A.H., Bule, M., Garcia-Perez, M., Chen, S. (2015). Simulation of the ozone pretreatment of wheat straw. Bioresource Technology, 196, 78-87. DOI: 10.1016/j.biortech.2015.07.022
[44] Mamleeva Nadezhda, A., Autlov Stanislav, A., Bazarnova Natal'ya, G., Lunin Valery, V. (2009). Delignification of softwood by ozonation. Pure and Applied Chemistry, 81(11), 2081-2091. DOI: 10.1351/PAC-CON-08-10-11

[45] Souza-Corrêa, J.A., Ridenti, M.A., Oliveira, C., Araújo, S.R., Amorim, J. (2013). Decomposition of Lignin from Sugar Cane Bagasse during Ozonation Process Monitored by Optical and Mass Spectrometries. The Journal of Physical Chemistry B, 117, 3110-3119. DOI: 10.1021/jp3121879

[46] Barros, R.d.R.O.d., Paredes, R.d.S., Endo, T., Bon, E.P.d.S., Lee, S.-H. (2013). Association of wet disk milling and ozonolysis as pretreatment for enzymatic saccharification of sugarcane bagasse and straw. Bioresource Technolo gy, $\quad 136, \quad 288-294$. D O I : 10.1016/j.biortech.2013.03.009

[47] Kádár, Z., Schultz-Jensen, N., Jensen, J.S., Hansen, M.A.T., Leipold, F., Bjerre, A.-B. (2015). Enhanced ethanol production by removal of cutin and epicuticular waxes of wheat straw by plasma assisted pretreatment. Biomass and Bioenergy, 81, 26-30. DOI: 10.1016/j.biombioe.2015.05.012

[48] Lim, M., Zulkifli, A.Z.S. (2018). Investigation of biomass surface modification using nonthermal plasma treatment. Plasma Science and Technology, 20, 115502. DOI: 10.1088/2058-6272/aac819

[49] Omar, W.N.N.W., Amin, N.A.S. (2021). Fractionation of Oil Palm Fronds (OPF) by Ozonolysis for Enhanced Sugar Production, Chemical Engineering Transactions, 83, 409414. DOI: $10.3303 / \mathrm{CET} 2183069$

[50] Binder, A., Pelloni, L., Fiechter, A., (1980) Delignification of straw with ozone to enhance biodegradability. European Journal of Applied Microbiology and Biotechnology, 11, 1-5, https://doi.org/10.1007/bf00514070

[51] Neely, W.C. (1984). Factors Affecting The Pretreatment of Biomass With Gaseous Ozone. Biotechnology and Bioengineering, 26, 59-65. DOI: 10.1002/bit.260260112

Selected and Revised Papers from International Conference on Sustainable Energy and Catalysis 2021 (ICSEC 2021) (https://engineering.utm.my/chemicalenergy/icsec2021/) (School of Chemical and Energy Engineering, Faculty of Engineering, Universiti Teknologi Malaysia, 16-17th February 2021) after Peer-reviewed by Scientific Committee of ICSEC 2021 and Peer-Reviewers of Bulletin of Chemical Reaction Engineering \& Catalysis.

Editors (Guest) in this ICSEC 2021 section are Nor Aishah Saidina Amin, Mohd Asmadi Mohammed Yussuf, Salman Raza Naqui, while Editor in Chief is I. Istadi. 